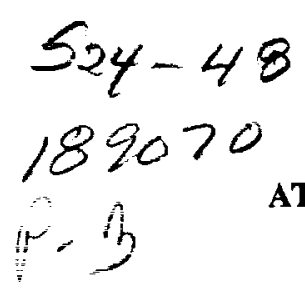

\title{
ATMOSPHERIC CORRECTION OF AVIRIS DATA IN OCEAN WATERS
}

\author{
Gregory Terrie and Robert Arnone \\ Naval Research Laboratory, Stennis Space Center
}

\section{INTRODUCTION}

Hyperspectral data offers unique capabilities for characterizing the ocean environment. The spectral characterization of the composition of ocean waters can be organized into biological and terrigenous components. Biological photosynthetic pigments in ocean waters have unique spectral ocean color signatures which can be associated with different biological species (Arnone et al, 1986). Additionally, suspended sediment has different scattering coefficients which result in ocean color signatures. Measuring the spatial distributions of these components in the maritime environments provides important tools for understanding and monitoring the ocean environment. These tools have significant applications in pollution, carbon cycle, current and water mass detection, location of fronts and eddies, sewage discharge and fate etc.

Ocean color has been used from satellite for describing the spatial variability of chlorophyll, water clarity $\left(k_{490}\right)$, suspended sediment concentration, currents etc. Additionally, with improved atmospheric correction methods, ocean color results have produced global products of spectral water leaving radiance $\left(\mathrm{L}_{\mathrm{w}}\right)$ (Feldman 1989). Ocean color results have clearly indicated strong applications for characterizing the spatial and temporal variability of bio-optical oceanography (Arnone et al, 1991).

These studies have been largely the results of advanced atmospheric correction techniques applied to multispectral imagery. The atmosphere contributes approximately $80 \%-90 \%$ of the satellite received radiance in the blue-green portion of the spectrum. In deep ocean waters, maximum transmission of visible radiance is achieved at $490 \mathrm{~nm}$. Conversely, nearly all of the light is absorbed by the water at wavelengths greater than about $650 \mathrm{~nm}$ and thus appears black. These spectral ocean properties are exploited by algorithms developed for the atmospheric correction used in satellite ocean color processing.

The objective of this study was to apply atmospheric correction techniques that were used for processing satellite Coastal Zone Color Scanner (CZCS) data to AVIRIS data. Quantitative measures of $\mathrm{L}_{\mathrm{w}}$ from AVIRIS will be compared with ship ground truth data and input into bio-optical models.

\section{METHODS}

Atmospheric correction of CZCS assumes a linear summation of the total radiance, $L_{1}(\lambda)$, sensed at the sensor (Gordon et al, 1983, Gordon and Clark, 1979). The atmospheric contribution is divided into the Rayleigh, $\mathrm{L}_{\mathrm{r}}(\lambda)$, component (molecular scattering) and the aerosol, $\mathrm{L}_{\mathbf{a}}(\lambda)$, component (Mie scattering). The volume scattering of the water, $\mathrm{L}_{w}(\lambda)$ (ocean color) is transmitted through the air sea interface, $t(\lambda)$. All of these parameters are related to the total radiance, $L_{t}(\lambda)$ by

$$
L_{r}(\lambda)=L_{r}(\lambda)+L_{a}(\lambda)+t(\lambda) L_{w}(\lambda)
$$


Assuming that the signal at $670 \mathrm{~nm}$ is due entirely to atmospheric effects and the aerosol optical thickness $\tau_{\mathrm{a}}(670)$ is proportional to $\tau_{\mathrm{a}}(\lambda)$, equation (1) can be written in terms of $\mathrm{L}_{w}(\lambda)$, at nadir, by

$$
t L_{w}(\lambda)=L_{r}(\lambda)-L_{r}(\lambda)-\frac{F_{0}(\lambda)}{F_{0}(670)}\left(\frac{\lambda}{670}\right)^{n}\left(L_{r}(670)-L_{r}(670)\right)
$$

where $F_{0}$ is the solar flux and $n$ is the angstrom coefficient.

This relationship was applied to AVIRIS data by expanding this generalized nadir equation to account for the angular atmospheric path radiance from the sensor altitude. The rayleigh component $L_{r}(\lambda)$ was computed using a multiple scattering model (Gordon et al, 1988). Both solar and sensor zenith and azimuth angles were computed for each pixel in the scene according to the date, time and location of data collection. The solar fluxes were assumed constants and the angstrom coefficient was varied.

Four spectral channels were used in processing CZCS ocean color data which were centered at $443 \mathrm{~nm}, 520 \mathrm{~nm}, 550 \mathrm{~nm}$, and $670 \mathrm{~nm}$ with a bandwidth of 20 $\mathrm{nm}$. The $443 \mathrm{~nm}$ channel represents the chlorophyll absorption wavelength which is inversely proportional to concentration (Clark 1980). The $520 \mathrm{~nm}$ and $550 \mathrm{~nm}$ channels characterize the hinge point in bio-optical ocean waters and arc related to sediment scattering. These bands were simulated using AVIRIS bands by averaging the two adjacent bands for each wavelength. Additionally, a $750 \mathrm{~nm}$ channel, analogous to the CZCS $750 \mathrm{~nm}$ band, was used as the atmospheric reference channel because of a problem with bottom reflectance at $670 \mathrm{~nm}$, especially in the shallow coastal regions. Each of the channels were calibrated for spectral radiance and for vignetting effects using the supplied correction data.

The atmospheric model was applied to an AVIRIS scene collected off Tampa Bay on April 3, 1990. This image has many different ocean regimes characterizing, shallow coastal waters with a uniform bottom reflectance, suspended sediment in the water, absorbing "yellow substance", and variability of coastal phytoplankton and clear waters. Ship measurements were collected by the University of South Florida (Carder et al, 1991) coincident with the overflight at three stations in which $\mathrm{L}_{w}(\lambda)$, chlorophyll, and the diffuse altenuation coefficient were measured.

\section{RESULTS}

The $443 \mathrm{~nm}$ channel is severely contaminated by the atmosphere and sensor noise such that little ocean features are observed. Atmospheric scattering diminishes in the $520 \mathrm{~nm}$ and $550 \mathrm{~nm}$ channels and ocean features can be recognized although not quantitative. Atmospheric correction using the $670 \mathrm{~nm}$ channel as the reference was applied to the scene ranging from clear waters to the coastal environments. In the near shore coastal waters, the AVIRIS data was shown to be correlated with the bathymetry since the reflectivity of the white bottom clearly dominated the water leaving radiance signal. The $670 \mathrm{~nm}$ channel was shown to be correlated with bottom reflectivity and therefore is not a good channel for only characterizing the atmosphere. Because of these non-zero $670 \mathrm{~nm}$ components, these is an overcorrection for the atmosphere. This results in negative radiance in areas where the bottom reflectance dominates the $670 \mathrm{~nm}$ channel. Since this is not possible the images were processed and negative values clipped to zero. The 
resulting atmospheric corrected $\mathbf{4 4 3}$ radiance was significantly improved and agreed favorably with the ship radiance data. Similarly, the $520 \mathrm{~nm}$ and $550 \mathrm{~nm}$ radiances were clipped to zero radiances in the shallow coastal waters. Comparison with the ship ground truth showed comparable results. Use of the $750 \mathrm{~nm}$ channel for aerosol correction in the coastal waters showed improvement versus the $670 \mathrm{~nm}$.

The atmospherically corrected data was then used to compute chlorophyll and $\mathbf{k}_{400}$ distributions. Results compared favorably with ship data and spatial distribution is clearly evident.

\section{CONCLUSIONS}

Because the atmosphere contributes a high percentage of the signal, the low signal to noise of AVIRIS limits the atmospheric removal process for deep ocean waters. The atmospheric correction techniques on CZCS can be applied to AVIRIS imagery to obtain quantitative estimates of the water leaving radiance. These results appear comparable with ship measurements. The high bottom reflectance observed in shallow waters severely restricts the conventional atmospheric correction technique of CZCS processing. Improved techniques are required to separate the volume scattering ocean color and the bottom reflectance radiance. The removal of the atmospheric contamination using the CZCS techniques can be improved substantially by using other spectral channels which are available using AVIRIS. Future efforts are focused on identifying optimal channels for atmospheric removal.

\section{ACKNOWLEDGEMENTS}

This work was sponsored by the NRL Code 9120 under program element number $61013 \mathrm{~N}$ and program manager Mark Landers.

\section{REFERENCES}

Arnone R.A, Bidigare R.R, Trees C.C. and Brooks J. "Comparison of the attenuation of spectral irradiance and phytoplankton pigments within frontal zones." Ocean Optics VI, Proc. SPIE, 637: 126-130. 1986

Arnone R.A, and Elenbass W. "Optical variability off the East coast using CZCS data", EOS Trans. 72(17), 1991.

Carder K., P. Reinersman, R. Chen, F. Muller-Karger, C. Davis, and M. Hamilton. "AVIRIS Calibration and Application in Coastal Oceanic Environments". Submitted to Remote Sensing of the Environment, (1992).

Clark, D.K. "Phytoplankton Pigment Algorithms for the Nimbus-7 CZCS", Oceanography from Space, J.R.F. Gower, Ed. (Plenum, NY, 1981), pp 227. 238.

Feldman, C, N. Kuring, C. Ng, W. Esaias, C. McClain, J. Elrod, N. Maynard, D. Endres, R. Evans, J. Brown, S. Walsh, M. Carle, and G. Podesta. "Ocean color: Availability of the global data set",EOS,70(23), 634-641, 1989.

Gordon H.R. and D. Clark. "Atmospheric Effects in the Remote Sensing of Phytoplankton Pigments", Boundary-Layer Meteorology 18 (1980), 299-313.

Gordon H.R., J.W. Brown, and R.H. Evans. "Exact Rayleigh scattering calculations for use with the Nimbus-7 Coastal Zone Color Scanner", Applied Optics 27(5), 862-871, 1988. 